\title{
水库浮游细菌生产和呼吸过程代谢内外源有机碳研究”
}

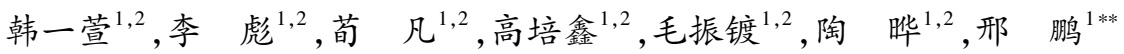 \\ (1: 中国科学院南京地理与湖泊研究所湖泊与环境国家重点实验室,南京 210008) \\ (2: 中国科学院大学, 北京 100049)
}

\begin{abstract}
摘 要: 全球气候变化和人类活动的加剧影响水生生态系统中溶解性有机碳( DOC) 的种类和浓度. 浮游细菌生产和呼吸 过程对碳源变化的响应, 可能影响水体乃至区域的碳循环特征. 本研究选取了南京市 11 座中小型水库,利用碳稳定同位 素技术和双端元混合模型定量分析浮游细菌在生产和呼吸代谢过程中对内外碳源的利用. 依据 DOC 中内外碳源的比例, 将 11 座水库划分为内源型水库 (内源碳占比 $>50 \%$ ) 和外源型水库 (外源碳占比 $>50 \%$ ). 内源型水库 DOC 浓度、叶绿素 $a$ 浓度以及营养指数均显著高于外源型水库. 分析发现, 水体初级生产力提高显著促进了浮游细菌对内源 DOC 的代谢速 率,内源型水库中浮游细菌生产利用内源碳速率提高,而外源型水库中浮游细菌呼吸分解内源碳速率提高. 不仅如此,水 体初级生产力提高促进外源型水库浮游细菌对 DOC 的总代谢速率. 水体溶解性无机氮和磷与浮游细菌的呼吸作用存在 显著的相关关系,内源型水库中随着营养盐浓度升高细菌呼吸作用减弱,而外源型水库中细菌呼吸作用增强. 上述研究 结果提示, 以外源输人为主的水体, 随着营养水平提高浮游细菌呼吸过程显著增加, 可能引起温室气体释放通量增加.
\end{abstract}

关键词: 水体营养状态;溶解性有机碳;生产速率;异养呼吸速率;稳定同位素示踪

\section{Metabolism of exogenous and endogenous dissolved organic carbon for bacterioplankton production and respiration in reservoirs*}

\author{
Han Yixuan ${ }^{1,2}$, Li Biao ${ }^{1,2}$, Xun Fan ${ }^{1,2}$, Gao Peixin ${ }^{1,2}$, Mao Zhendu ${ }^{1,2}$, Tao Ye ${ }^{1,2}$ \& Xing Peng ${ }^{1 * *}$ \\ (1: State Key Laboratory of Lake and Environment, Nanjing Institute of Geography and Limnology, Chinese Academy of Sci- \\ ences, Nanjing 210008, P.R.China) \\ (2: University of Chinese Academy of Sciences, Beijing 100049, P.R.China)
}

\begin{abstract}
Global climate change and intensive anthropogenic activities are affecting the variety and contents of dissolved organic carbons (DOC) in the aquatic systems. The potential response of planktonic bacteria to the changing carbon sources could influence the characteristics of carbon cycling in local waterbodies and even regional areas. In this study, eleven small and medium reservoirs were selected to quantificationally analyze the utilization of exogenous and endogenous organic carbon during the bacterial production and respiration using the stable carbon isotope analysis and a two-source mixing model. The eleven reservoirs were subsequently classified into exogenous (exogenous DOC/DOC $>50 \%$ ) and endogenous (endogenous DOC/DOC $>50 \%$ ) reservoirs according to the ratio of the two kinds of DOC sources. Results indicated that the concentrations of DOC and chlorophyll-a (Chl.a) and trophic level index were significantly higher in the endogenous reservoirs than in the exogenous reservoirs. It was observed that the bacterial metabolic rates of endogenous DOC could be significantly elevated with increasing primary productivity in the reservoirs. Specifically, the metabolic rates of endogenous DOC were improved for bacterial production in the endogenous reservoirs and bacterial respiration in the exogenous reservoirs, respectively. Moreover, the overall bacterial metabolic rates of DOC were promoted in the exogenous reservoirs with increasing primary productivity. In addition, a significant relationship was observed between dissolved inorganic nitrogen/phosphorus and bacterial respiration, indicating that the bacterial respiration could be suppressed with increasing nutrition concentration in the endogenous reservoirs but be strengthened with increasing nutrition concentration in the exogenous reservoirs. These results suggested that the release flux of greenhouse gas can be increased owing to the improvement of bacte-
\end{abstract}

* 2021-04-14 收稿;2021-05-11 收修改稿.

国家自然科学基金项目 (31670505, 31722008) 和中国科学院青年创新促进会项目(2014273) 联合资助.

** 通信作者;E-mail: pxing@ niglas.ac.cn. 
rial respiration with the elevating eutrophication levels in the exogenous reservoirs.

Keywords: Aquatic trophic level; dissolved organic carbon; production rate; heterotrophic respiration rate; stable isotopic signature

作为淡水生态系统中有机碳的主要载体, 溶解性有机碳 (DOC) 占湖泊、水库等内陆水体总有机碳的 $80 \%$ 以上, 对水体的理化性质和微生物的生化反应有着重要作用 ${ }^{[1]}$. DOC 按照来源可以分为两类,一类是内 源性 DOC, 主要来自水体初级生产者 (浮游藻类、水生植物以及附着藻类) 光合作用产物的释放以及内源性 碎屑物质的分解; 另一类是外源性 DOC, 主要来自以 C3 植物为主的陆地初级生产者以及土壤渗滤液中的可 溶解部分 ${ }^{[2-3]}$. 有的研究表明, 以浮游细菌为主的微生物是有机碳代谢过程的主要参与者, 在其代谢过程中 不仅能够利用水体中的内源性 DOC 还能够利用外源性 DOC ${ }^{[4-5]}$. 在淡水生态系统中, DOC 的代谢主要是通 过细菌的生产和呼吸作用进行的, 降解消耗 DOC 的过程驱动着水生食物网的物质循环和能量流通 ${ }^{[6-7]}$. 大 量研究结果表明, 浮游细菌会根据有机碳底物的化学性质和代谢的难易程度, 选择性地利用内外源碳以用 于生产和呼吸代谢 ${ }^{[8-9]}$. 在瑞典中东部的浅水型湖泊中, $\operatorname{Sundh}^{[8]}$ 发现与高分子量 $(>10000)$ 的 DOC 相比, 细 菌对低分子量 $(<1000)$ 的 DOC 利用率更高. 但是, 以往研究主要针对的是中高纬地区寡营养型湖泊中细菌 的代谢特征 ${ }^{[5,10]}$, 缺乏对中低纬地区较高营养水平的淡水系统中细菌碳代谢策略的探究.

水库具有独特的水力学特征, 诸如水力停留时间长、水体流动性差以及自净功能较差等特性 ${ }^{[11]}$. 致使 近年来, 水库的富营养化问题日益严重, 藻类周期性繁殖现象时有发生 ${ }^{[12-13]}$. 在长江中下游地区, 水库分布 众多, 受藻类繁殖和外源有机碳输人的共同影响, 水库 DOC 的来源与构成日趋复杂 ${ }^{[5,14]}$. 浮游细菌在碳代谢 过程中, 是否对水库中内外源 DOC 的利用存在偏好, 能否对细菌利用内外源 DOC 进行生产和呼吸过程做准 确的定量分析, 是本研究拟解决的问题. 对这些问题的探究, 将有助于揭示浮游细菌分配内外源碳以进行代 谢的生物学机制, 推动水库生态系统碳循环的研究.

\section{1 材料与方法}

\section{1 研究区概况与样品采集}

1.1 .1 研究区概况 南京市位于我国东部长江下游地 区, 属宁镇扬丘陵地区, 受亚热带湿润气候影响, 四 季分明,雨水充沛, 水域面积达 $11 \%$ 以上,拥有众多 水库,其中中小型水库多达 250 座 $^{[12]}$. 陈美军等 ${ }^{[12]}$ 对南京市 37 座水库进行了水质评价, 发现富营养和 中营养水库占比分别为 $55 \%$ 和 $45 \%$,均处于较高的 营养水平. 因此,本研究于 2019 年秋季至 2020 年夏 季期间对南京市 11 座水库 (碾坨坝、泥桥、河王坝、 黄山、山湖、傅湾、平山、海王庄、方便、姚家以及老鸭 坝水库) 进行了现场调研与采样(图 1).

1.1 .2 表层水样采集 根据水库面积的大小均匀布置 $2 \sim 3$ 个采样点, 利用 Niskin 采水器 (General Oceanic, $\mathrm{USA}$ ) 在水面以下 $0.5 \mathrm{~m}$ 处采集 $20 \mathrm{~L}$ 水样, 置于提前 洗净的聚乙烯采样瓶中, 于 $4^{\circ} \mathrm{C}$ 冷藏箱内保存, 并于 $2 \mathrm{~h}$ 内运回实验室, 用于水体理化性质的分析与浮游 细菌的分离培养.

1.1.3 内源 DOC 样品采集 在采样船行进过程中, 利 用 $25^{\#}$ 浮游植物网收集水体中的藻类, 拖行约 15 $\mathrm{min}$, 将采集到的浮游藻类转移至提前洗净的 $500 \mathrm{~mL}$ 聚乙烯采样瓶中, 于 $4^{\circ} \mathrm{C}$ 冷藏箱内保存, 并于 $2 \mathrm{~h}$ 内

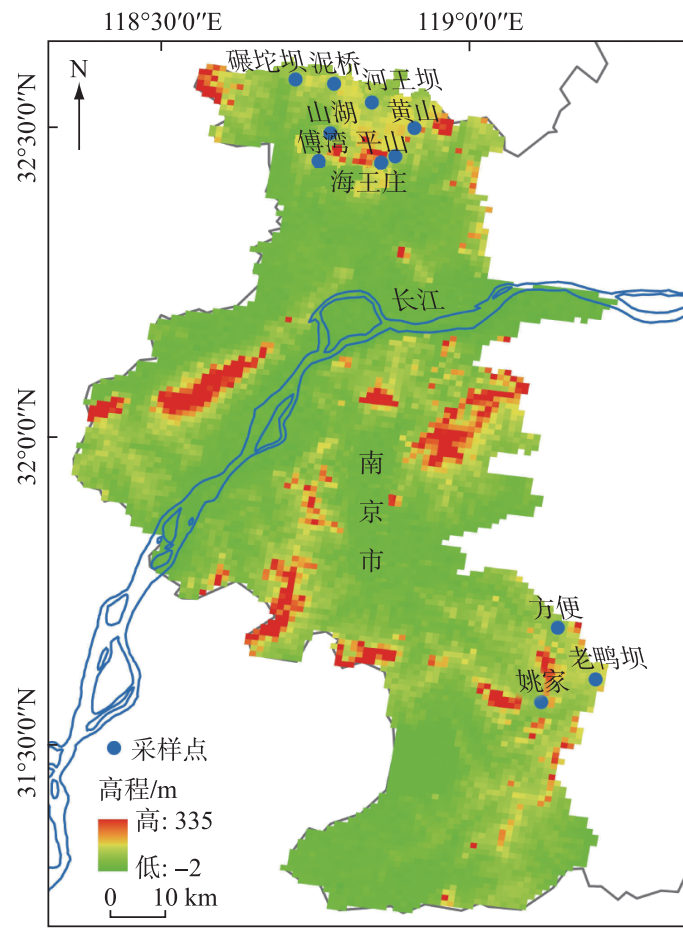

图 1 本研究中水库的地理位置分布

Fig. 1 Geographical distribution of the reservoirs in this study 
运回实验室,用于水体内源 DOC 的分析.

1.1.4 外源 DOC 样品采集 在水库沿岸 $10 \mathrm{~m}$ 范围内, 利用铁铲与铌子采集沿岸表层土壤样品以及优势植物 的枯叶残体等陆源输人的有机碳样品, 置于干净的聚乙烯密封袋中, 用于水体外源 DOC 的分析.

\section{2 水库理化指标的测定}

利用多参数水质分析仪 (YSI 6600, Xylem Inc, USA) 在采样现场测定水温、 $\mathrm{pH}$ 和溶解氧 (DO) 等指标. 在实验室中, 利用热乙醇法萃取后测定叶绿素 $a($ Chl. $a$ ) 浓度, 利用总有机碳分析仪 (TOC-V CPN, Shimadzu, Japan) 测定水库水体中的 DOC 浓度. 采用流动分析仪 (San plus, Skalar, Netherlands) 测定水体的总氮 $(\mathrm{TN}) 、$ 总磷 $(\mathrm{TP}) 、$ 磷酸根 $\left(\mathrm{PO}_{4}^{3-}\right)$ 、硝酸根 $\left(\mathrm{NO}_{3}^{-}\right)$等营养盐浓度 ${ }^{[15]}$. 利用营养级指数 $(T L I)$ 描述水库的营养状 态, 选取 Chl. $a$ 和 TN 浓度两个指标作为评价 $T L I$ 的主要因子 ${ }^{[16-17]}$, 将水库营养级水平分别为贫营养型 $(T L I$ $(\Sigma) \leqslant 30) 、$ 中营养型 $(30<T L I(\Sigma) \leqslant 50)$ 、富营养型 $(50<T L I(\Sigma) \leqslant 60)$ 、中度富营养型 $(60<T L I(\Sigma) \leqslant 70)$ 以及重度富营养型 $(T L I(\Sigma)>70)$.

\section{3 水体 DOC 以及内外碳源中碳稳定同位素的测定}

1.3.1 水体 DOC 碳稳定同位素的测定 取 $250 \mathrm{~mL}$ 水样,经 $0.22 \mu \mathrm{m}$ 聚碳酸酯滤膜 (Waterman, USA) 过滤,在 $-70^{\circ} \mathrm{C}$ 下冻干后, 将残留的渣体置于底部放有 $5 \mathrm{~mol} / \mathrm{L}$ 浓盐酸的干燥器中酸熏 $48 \mathrm{~h}$, 在 $45^{\circ} \mathrm{C}$ 下烘干, 称量约 2 $\mathrm{mg}$ 样品置于锡杯中, 利用同位素质谱仪 (Delta Plus, Finnigan, USA) 测定水体 DOC 的碳稳定同位素 $\left(\delta^{13} \mathrm{C}\right.$ ) 特征值 ${ }^{[18]}$.

1.3.2 内源 DOC 碳稳定同位素的测定 利用过滤装置将采集的内源 DOC 样品中的浮游藻类转移至 $0.7 \mu \mathrm{m}$ GF/F 滤膜 (Waterman, USA) 上, 随后将滤膜置于一次性培养皿中冻干. 与上述方法类似, 将冻干后的内源碳 样品酸熏并烘干后, 称量约 $0.2 \mathrm{mg}$ 样品置于锡杯中, 利用同位素质谱仪 (Delta Plus, Finnigan, USA) 测定水 库内源 DOC 的碳稳定同位素特征值 ${ }^{[18]}$.

1.3.3 外源 DOC 碳稳定同位素的测定 利用去离子水将采集的植物样品洗净, 在 $-70^{\circ} \mathrm{C}$ 下冻干, 经过均匀研 磨后, 在 $3 \mathrm{~mol} / \mathrm{L}$ 的盐酸中浸泡 $14 \mathrm{~h}$, 利用纯水冲洗至中性, 转移至一次性培养血中烘干, 称量约 $0.5 \mathrm{mg}$ 样品 置于锡杯中; 称取约 $50 \mathrm{~g}$ 低温烘干的土壤放人盛有 $250 \mathrm{~mL}$ 蒸馏水的三角瓶中, 常温下震荡浸提 $30 \mathrm{~min}$, 高 速离心 $10 \mathrm{~min}$, 上清液用 $0.22 \mu \mathrm{m}$ 滤膜过滤 ${ }^{[19]}$, 后续测定方法与水体 DOC 碳稳定同位素相同, 利用同位素 质谱仪 (Delta Plus, Finnigan, USA) 测定水库外源 DOC 的碳稳定同位素特征值.

\section{4 浮游细菌的分离培养与代谢产物中碳稳定同位素的测定}

1.4.1 浮游细菌的生产和呼吸过程观测 取 $800 \mathrm{~mL}$ 水样, 经 $0.7 \mu \mathrm{m} \mathrm{GF} / \mathrm{F}$ 滤膜 (Waterman, USA) 过滤后, 作 为浮游细菌样本, 置于自制的浮游细菌代谢装置中 (专利号: ZL202020314401.5), 用 $3 \mathrm{~mol} / \mathrm{L}$ 盐酸调节 $\mathrm{pH}$ 至 2.5 以下, 待水体中溶解性无机碳 (DIC) 基本排尽, 加人碱液调节 $\mathrm{pH}$ 至初始水平. 随后通人氮气, 排净装置 中的 $\mathrm{CO}_{2}$ 后, 向装置中通人不含 $\mathrm{CO}_{2}$ 的空气 $30 \mathrm{~min}$, 密封装置瓶, 在培养箱中培养 $48 \mathrm{~h}$, 温度设定与采样时的 水库温度一致.

1.4.2 细菌 DOC 代谢速率的测定 在细菌培养的初始和结束阶段, 分别从培养装置中抽取 $30 \mathrm{~mL}$ 水样, 利用 总有机碳分析仪 (TOC-V CPN, Shimadzu, Japan) 测定细菌代谢初始和结束阶段水体的 DOC 与 DIC 浓度. 浮 游细菌 DOC 代谢速率 $(\mu \mathrm{g} /(\mathrm{L} \cdot \mathrm{h}))$ 的计算公式为:

$$
\text { DOC 代谢速率 }=\left(D O C_{\text {初 }}-D O C_{\text {末 }}\right) V \times 1000 / t
$$

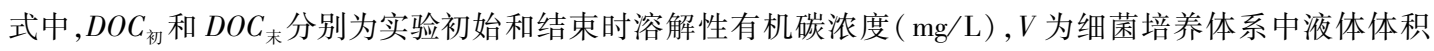
( $\mathrm{L}), t$ 为培养时间 $(\mathrm{h})$.

1.4.3 细菌呼吸代谢速率与产物中碳稳定同位素的测定 在细菌培养的初始和结束阶段, 分别从培养装置的 取气口抽取 $25 \mathrm{~mL}$ 气体样品, 利用气相色谱一温室气体仪 (7890B, Agilent, USA) 测定代谢初始和结束阶段 装置中的 $\mathrm{CO}_{2}$ 浓度 $(\mathrm{mg} / \mathrm{L})$. 呼吸碳代谢速率 $(\mu \mathrm{g} /(\mathrm{L} \cdot \mathrm{h}))$ 的计算公式为:

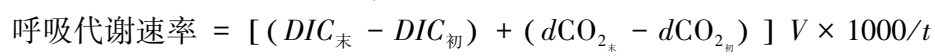

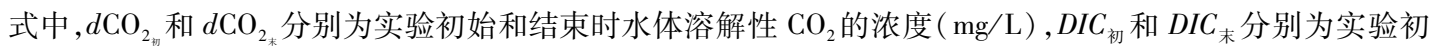
始和结束时溶解性无机碳浓度 $(\mathrm{mg} / \mathrm{L})^{[20]}$.

基于细菌培养结束阶段抽取的气体样品, 利用碳稳定同位素仪 (G2201-i, Picarro, USA) 测定浮游细菌 
呼吸代谢产物中的碳稳定同位素特征值.

1.4.4 细菌生产代谢速率与生物体碳稳定同位素的测定 通常认为, 浮游细菌的代谢主要由呼吸代谢和生产 代谢构成 ${ }^{[14]}$. 因此, 在本研究中利用质量守恒法来测定浮游细菌的生产代谢速率计算公式为:

$$
\text { 生产代谢速率 }=\text { DOC 代谢速率 }- \text { 呼吸代谢速率 }
$$

在细菌培养结束后, 取反应装置中约 $600 \mathrm{~mL}$ 水样, 经 $0.7 \mu \mathrm{m} \mathrm{GF} / \mathrm{F}$ 滤膜 (Waterman, USA) 和 $0.2 \mu \mathrm{m}$ 纯 无机 Anodisc ${ }^{\mathrm{TM}} 47$ 氧化铝滤膜 (Waterman, USA) 依次过滤, 对浮游细菌进行富集. 随后, 将附有浮游细菌的 滤膜置于一次性培养血中冻干, 并使用玛瑙研针研磨, 使样品通过孔径为 $0.075 \mathrm{~mm}$ 的篮网. 称量约 $10 \mathrm{mg}$ 样 品置于锡杯中, 利用同位素质谱仪 (Delta Plus, Finnigan, USA) 测定细菌生产代谢产物中的碳稳定同位素特 征值.

\section{5 水体 DOC 以及浮游细菌代谢产物中的内外碳源贡献率}

为研究水库内外碳源对水体 DOC 和浮游细菌代谢产物的贡献率, 本研究利用双元混合模型计算了水体 DOC 中内外碳源的占比, 以及浮游细菌在生产和呼吸代谢过程中对两种碳源的利用率 ${ }^{[21]}$. 计算公式为:

$$
\begin{aligned}
\delta^{13} \mathrm{C}_{\text {组分 }}= & f_{1} \cdot \delta^{13} \mathrm{C}_{\text {外 }}+f_{2} \cdot \delta^{13} \mathrm{C}_{\text {内 }} \\
& f_{1}+f_{2}=1
\end{aligned}
$$

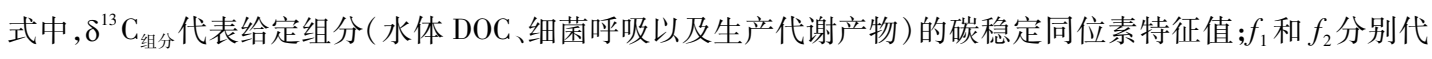

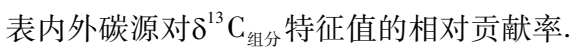

\section{6 数据分析方法}

运用 Excel 2007、Origin 9.0 等软件对实验数据进行处理、图形绘制. 采用 SPSS 20.0 软件进行数据相关 性分析. 此外, 采用 ArcGIS 10.2 软件绘制水库的地理位置图.

\section{2 结果与分析}

\section{1 水体基本理化环境特征及碳源类型}

本研究中 11 座水库的位置及基础理化指标如表 1 所示. 选取的研究区多为浅水型水库,各个采样点水 深不超过 $5 \mathrm{~m}$. 采样期间, 11 座水库的水温在 $8.85 \sim 27.35^{\circ} \mathrm{C}$ 之间, 季节性差异较大 (表 1). 水体的 $\mathrm{pH}$ 值在 7.87 8.90 之间, 均为弱碱性水库. 水库溶解氧浓度在 $(6.74 \pm 0.56) \sim(12.35 \pm 0.19) \mathrm{mg} / \mathrm{L}$ 之间变化. 浮游细 菌细菌丰度在 $10^{5} \sim 10^{6}$ 数量级之间 (表 1 ).

在 11 座水库中,内外源有机碳稳定同位素的端元值在不同水库中呈现出较大的差异 (表 2), 藻类等内 源碳同位素的特征值范围为 $-34.24 \% 0 \sim-23.59 \%$, 外源 DOC 碳同位素特征值最小值为 $-27.93 \%$ 。（碾坨坝水 库), 最大值为 $-19.59 \%$ (海王庄水库). 测定结果显示水体 DOC 碳稳定同位素的特征值范围为 $-28.96 \%$ $-24.04 \%$. 以上 3 种有机碳碳稳定同位素的特征值在大多数水库中均呈现出以下大小关系: $\delta^{13} \mathrm{C}_{\text {外 }}>\delta^{13} \mathrm{C}_{\mathrm{DOC}}>$

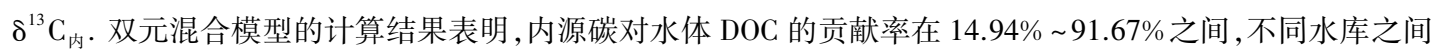
存在较大的差异; 相应地, 以植物调落物和岸边土壤为主的外源碳对 DOC 的贡献率范围为 $8.33 \% \sim 85.06 \%$. 根据内、外源有机碳的贡献率, 将 11 座水库划分为两种类型, 即内源碳占据主导 (内源碳贡献率>50\%) 的水 库一内源型水库, 包括海王庄、傅湾、泥桥、平山、碾坨坝 5 座水库, 以及外源碳占据主导 (外源碳贡献率> $50 \%$ ) 的水库一一外源型水库,包括山湖、老鸭坝、河王坝、黄山、姚家以及方便 6 座水库 (表 2). 基于指数模 型 Exponential 的拟合结果, 随着水库 Chl. $a$ 浓度升高, 内源碳对水体 DOC 的贡献率显著增加, 拟合方程为 $y=-0.59+0.90807^{-0.08045-0.03373 x}\left(R^{2}=0.55, P<0.01\right.$, 图 2).

作为水库浮游细菌代谢的主要碳源, 基于水库碳源类型划分 (图 3a), 外源型水库中 DOC 的平均浓度为 $(9.86 \pm 1.12) \mathrm{mg} / \mathrm{L}$, 内源型水库 DOC 平均浓度达到 $(15.71 \pm 3.35) \mathrm{mg} / \mathrm{L}$, 因此内源型水库水体 DOC 的浓度 显著高于外源型水库 $(P<0.01)$ (图 $3 \mathrm{~b}$ ). $\mathrm{PO}_{4}^{3-}$ 是淡水生态系统中重要的营养盐离子, 在内源型水库的浓度也 显著高于外源型水库 $(P<0.01)$ (图 3c). 同样, Chl. $a$ 浓度在两种类型水库间呈现显著的差异, Chl. $a$ 在外源 型水库中的平均浓度为 $(12.11 \pm 6.14) \mu \mathrm{g} / \mathrm{L}$, 显著低于内源型水库的平均浓度 $((97.42 \pm 60.02) \mu \mathrm{g} / \mathrm{L})$ (图 $3 \mathrm{~d}$ ). 营养级指数计算结果表明,外源型水库的整体营养水平低于内源型水库 $(P<0.01)$ (图 3e). 此外, 外源 型水库水体的 DOC/TN 比值 $(21.62 \pm 9.61)$ 显著高于内源型水库 $(10.52 \pm 2.73)(P<0.01)$ (图 3f). 但细菌计数 
表 1 本研究中 11 座水库的水体理化性质

Tab.1 Physicochemical properties of water samples in the 11 reservoirs in this study

\begin{tabular}{|c|c|c|c|c|c|c|c|c|c|}
\hline 采样时间 & 水库 & 采样点 & 纬度 & 经度 & $\begin{array}{l}\text { 溶解氧/ } \\
(\mathrm{mg} / \mathrm{L})\end{array}$ & $\mathrm{pH}$ & $\begin{array}{c}\text { 温度/ } \\
{ }^{\circ} \mathrm{C}\end{array}$ & $\begin{array}{c}\text { 水深/ } \\
\mathrm{m}\end{array}$ & $\begin{array}{l}\text { 细菌丰度/ } \\
\text { (cells } / \mathrm{mL} \text { ) }\end{array}$ \\
\hline \multirow[t]{9}{*}{$2019-11-20$} & 老鸭坝 & 1 & $31^{\circ} 36^{\prime} 16^{\prime \prime} \mathrm{N}$ & $119^{\circ} 11^{\prime} 44^{\prime \prime} \mathrm{E}$ & 9.68 & 8.26 & 20.30 & 3.50 & $9.92 \times 10^{5}$ \\
\hline & & 2 & $31^{\circ} 36^{\prime} 28^{\prime \prime} \mathrm{N}$ & $119^{\circ} 11^{\prime} 52^{\prime \prime} \mathrm{E}$ & 10.00 & 8.42 & 19.90 & 4.00 & $1.03 \times 10^{6}$ \\
\hline & & 3 & $31^{\circ} 36^{\prime} 27^{\prime \prime} \mathrm{N}$ & $119^{\circ} 11^{\prime} 21^{\prime \prime} \mathrm{E}$ & 9.58 & 8.39 & 20.90 & 2.90 & $1.09 \times 10^{6}$ \\
\hline & 姚家 & 1 & $31^{\circ} 20^{\prime} 3^{\prime \prime} \mathrm{N}$ & $11^{\circ} 36^{\prime} 46^{\prime \prime} \mathrm{E}$ & 10.86 & 8.49 & 21.20 & 2.90 & $9.88 \times 10^{5}$ \\
\hline & & 2 & $31^{\circ} 20^{\prime} 39^{\prime \prime} \mathrm{N}$ & $119^{\circ} 36^{\prime} 52^{\prime \prime} \mathrm{E}$ & 11.13 & 8.58 & 21.80 & 3.50 & $6.60 \times 10^{5}$ \\
\hline & & 3 & $31^{\circ} 20^{\prime} 28^{\prime \prime} \mathrm{N}$ & $119^{\circ} 36^{\prime} 41^{\prime \prime} \mathrm{E}$ & 10.00 & 8.40 & 21.90 & 4.20 & $9.96 \times 10^{5}$ \\
\hline & 方便 & 1 & $31^{\circ} 41^{\prime} 47^{\prime \prime} \mathrm{N}$ & $119^{\circ} 7^{\prime} 36^{\prime \prime} \mathrm{E}$ & 9.33 & 8.29 & 20.80 & 4.50 & $4.02 \times 10^{5}$ \\
\hline & & 2 & $31^{\circ} 41^{\prime} 18^{\prime \prime} \mathrm{N}$ & $119^{\circ} 7^{\prime} 50^{\prime \prime} \mathrm{E}$ & 10.13 & 8.55 & 21.90 & 2.80 & $3.66 \times 10^{5}$ \\
\hline & & 3 & $31^{\circ} 40^{\prime} 46^{\prime \prime} \mathrm{N}$ & $119^{\circ} 7^{\prime} 57^{\prime \prime} \mathrm{E}$ & 10.79 & 8.57 & 22.00 & 3.40 & $1.29 \times 10^{5}$ \\
\hline \multirow[t]{5}{*}{$2019-12-05$} & 山湖 & 1 & $32^{\circ} 17^{\prime} 15^{\prime \prime} \mathrm{N}$ & $118^{\circ} 27^{\prime} 37^{\prime \prime} \mathrm{E}$ & 11.19 & 8.68 & 8.50 & 2.30 & $1.18 \times 10^{5}$ \\
\hline & & 2 & $32^{\circ} 17^{\prime} 23^{\prime \prime} \mathrm{N}$ & $118^{\circ} 27^{\prime} 48^{\prime \prime} \mathrm{E}$ & 12.27 & 8.60 & 9.10 & 2.50 & $1.93 \times 10^{6}$ \\
\hline & & 3 & $32^{\circ} 17^{\prime} 35^{\prime \prime} \mathrm{N}$ & $118^{\circ} 27^{\prime} 41^{\prime \prime} \mathrm{E}$ & 12.56 & 8.59 & 9.20 & 1.50 & $1.07 \times 10^{6}$ \\
\hline & 傅湾 & 1 & $32^{\circ} 15^{\prime} 49^{\prime \prime} \mathrm{N}$ & $118^{\circ} 27^{\prime} 0.3^{\prime \prime} \mathrm{E}$ & 12.11 & 8.47 & 8.80 & 1.80 & $9.53 \times 10^{5}$ \\
\hline & & 2 & $32^{\circ} 15^{\prime} 51^{\prime \prime} \mathrm{N}$ & $118^{\circ} 28^{\prime} 11^{\prime \prime} \mathrm{E}$ & 12.50 & 8.44 & 8.90 & 1.50 & $8.93 \times 10^{5}$ \\
\hline \multirow[t]{4}{*}{$2020-05-06$} & 平山 & 1 & $32^{\circ} 26^{\prime} 25^{\prime \prime} \mathrm{N}$ & $118^{\circ} 50^{\prime} 40^{\prime \prime} \mathrm{E}$ & 7.22 & 7.63 & 20.40 & 1.90 & $9.15 \times 10^{5}$ \\
\hline & & 2 & $32^{\circ} 26^{\prime} 22^{\prime \prime} \mathrm{N}$ & $118^{\circ} 51^{\prime} 3.9^{\prime \prime} \mathrm{E}$ & 6.25 & 8.3 & 21.20 & 1.70 & $1.43 \times 10^{6}$ \\
\hline & 海王庄 & 1 & $32^{\circ} 27^{\prime} 10^{\prime \prime} \mathrm{N}$ & $118^{\circ} 52^{\prime} 0.8^{\prime \prime} \mathrm{E}$ & 7.99 & 7.98 & 21.90 & 2.10 & $2.91 \times 10^{5}$ \\
\hline & & 2 & $32^{\circ} 27^{\prime} 9.4^{\prime \prime} \mathrm{N}$ & $118^{\circ} 52^{\prime} 16^{\prime \prime} \mathrm{E}$ & 6.88 & 7.98 & 21.70 & 2.40 & $3.18 \times 10^{5}$ \\
\hline \multirow[t]{4}{*}{$2020-05-23$} & 河王坝 & 1 & $32^{\circ} 32^{\prime} 14^{\prime \prime} \mathrm{N}$ & $118^{\circ} 49^{\prime} 59^{\prime \prime} \mathrm{E}$ & 8.66 & 8.65 & 26.50 & 1.80 & $7.87 \times 10^{5}$ \\
\hline & & 2 & $32^{\circ} 31^{\prime} 52^{\prime \prime} \mathrm{N}$ & $118^{\circ} 49^{\prime} 56^{\prime \prime} \mathrm{E}$ & 8.41 & 8.66 & 27.33 & 1.80 & $9.81 \times 10^{5}$ \\
\hline & 黄山 & 1 & $32^{\circ} 29^{\prime} 52^{\prime \prime} \mathrm{N}$ & $118^{\circ} 54^{\prime} 10^{\prime \prime} \mathrm{E}$ & 7.51 & 8.59 & 25.84 & 2.60 & $1.25 \times 10^{5}$ \\
\hline & & 2 & $32^{\circ} 29^{\prime} 42^{\prime \prime} \mathrm{N}$ & $118^{\circ} 53^{\prime} 56^{\prime \prime} \mathrm{E}$ & 7.39 & 8.44 & 25.01 & 2.50 & $1.19 \times 10^{5}$ \\
\hline \multirow[t]{4}{*}{$2020-06-06$} & 碾拓坝 & 1 & $32^{\circ} 34^{\prime} 44^{\prime \prime} \mathrm{N}$ & $118^{\circ} 43^{\prime} 19^{\prime \prime} \mathrm{E}$ & 8.80 & 8.62 & 26.70 & 3.50 & $3.13 \times 10^{6}$ \\
\hline & & 2 & $32^{\circ} 34^{\prime} 48^{\prime \prime} \mathrm{N}$ & $118^{\circ} 42^{\prime} 55^{\prime \prime} \mathrm{E}$ & 8.43 & 8.95 & 27.50 & 3.80 & $3.26 \times 10^{6}$ \\
\hline & 泥桥 & 1 & $32^{\circ} 34^{\prime} 27^{\prime \prime} \mathrm{N}$ & $118^{\circ} 46^{\prime} 57^{\prime \prime} \mathrm{E}$ & 8.55 & 8.80 & 27.80 & 4.20 & $1.25 \times 10^{6}$ \\
\hline & & 2 & $32^{\circ} 34^{\prime} 20^{\prime \prime} \mathrm{N}$ & $118^{\circ} 46^{\prime} 54^{\prime \prime} \mathrm{E}$ & 8.90 & 8.99 & 26.90 & 4.60 & $8.89 \times 10^{5}$ \\
\hline
\end{tabular}

表 2 水库水体 DOC 以及内外碳源稳定同位素的特征值和贡献率 *

Tab.2 Characteristic values of the stable carbon isotope for the DOC, the endogenous, and exogenous carbon sources in the reservoirs and the contribution of endogenous carbon to DOC

\begin{tabular}{|c|c|c|c|c|c|c|}
\hline 水库 & $\delta^{13} \mathrm{C}_{\mathrm{DOC}} / \%$ & $\delta^{13} \mathrm{C}_{\text {内 }} / \% 0$ & $\delta^{13} \mathrm{C}_{\text {外 }} / \%$ & $\mathrm{DOC}_{\text {内 }} / \%$ & 水库类型 & 外源碳端元值指示物 \\
\hline 老鸭坝 & -27.55 & -33.45 & -26.36 & $16.17 \pm 0.13$ & 外源型 & 乌柏 (Sapium sebiferum Roxb.) 树叶 \\
\hline 山湖 & -28.03 & -31.35 & -27.41 & $14.94 \pm 0.09$ & 外源型 & 土壤浸提液 \\
\hline 河王坝 & -25.82 & -23.58 & -26.88 & $30.90 \pm 0.15$ & 外源型 & 杨 (Populus L.) 树叶 \\
\hline 黄山 & -24.04 & -28.94 & -21.79 & $31.46 \pm 0.02$ & 外源型 & 菖蒲 (Acorus calamus L.) \\
\hline 姚家 & -28.96 & -34.24 & -26.28 & $33.67 \pm 0.01$ & 外源型 & 珊瑚树 (Viburnum odoratissimum) \\
\hline 方便 & -28.31 & -32.35 & -26.12 & $35.44 \pm 0.37$ & 外源型 & 杨树叶 \\
\hline 碾坨坝 & -25.38 & -23.59 & -27.93 & $58.80 \pm 0.05$ & 内源型 & 枸骨 (Ilex cornuta) 树叶 \\
\hline 平山 & -25.71 & -27.93 & -21.74 & $65.17 \pm 0.03$ & 内源型 & 知风草 (Eragrostis ferruginea) \\
\hline 泥桥 & -27.44 & -29.37 & -21.48 & $75.73 \pm 0.07$ & 内源型 & 萎蒿( Artemisia selengensis Turcz. ex Bess.) \\
\hline 傅湾 & -28.10 & -28.32 & -26.86 & $85.00 \pm 0.04$ & 内源型 & 白茅(Imperata cylindrica Beauv.) \\
\hline 海王庄 & -26.38 & -26.99 & -19.59 & $91.67 \pm 0.02$ & 内源型 & 土壤浸提液 \\
\hline
\end{tabular}

* DOC 内表示水体 DOC 中内源碳的占比. 
结果表明, 内外源型水库在浮游细菌数量上并无明显差异 $(P>0.05)$ ( 表 1$)$.

\section{2 浮游细菌生产和呼吸过程碳代谢特征}

11 座水库浮游细菌培养 $48 \mathrm{~h}$ 后, 细菌生物体中碳稳定 同位素特征值 $\left(\delta^{13} \mathrm{C}_{\text {生产 }}\right)$ 的范围为 $-29.83 \% 0 \sim-22.39 \%$, 其 中, 方便水库最低而平山水库最高, 与内外碳源稳定同位素 端元值相比变化范围较小 (表 3). 双端元混合模型计算显 示, 外源型水库中, 内源碳对生产过程的贡献率为 $24.96 \%$ $78.31 \%$; 内源型水库中, 内源碳对生产过程的贡献率为 $10.55 \% \sim 90.50 \%$. 外源型水库中, 方便水库浮游细菌生产代 谢碳速率最高, 为 $(12.53 \pm 0.10) \mu \mathrm{g} /(\mathrm{L} \cdot \mathrm{h})$, 同时细菌生产代 谢内源碳速率也是最高 $((0.58 \pm 0.16) \mu \mathrm{g} /(\mathrm{L} \cdot \mathrm{h}))$ (图 $4 \mathrm{a})$. 内源型水库中, 海王庄水库浮游细菌生产代谢碳速率最高, 为 $(15.63 \pm 1.06) \mu \mathrm{g} /(\mathrm{L} \cdot \mathrm{h})$. 平山水库与海王庄水库浮游细 菌生产代谢外源碳速率显著高于其他水库 $(P<0.01)$, 分别为 $(11.25 \pm 0.22)$ 和 $(8.96 \pm 0.71) \mu \mathrm{g} /(\mathrm{L} \cdot \mathrm{h})($ 图 $4 \mathrm{a})$.

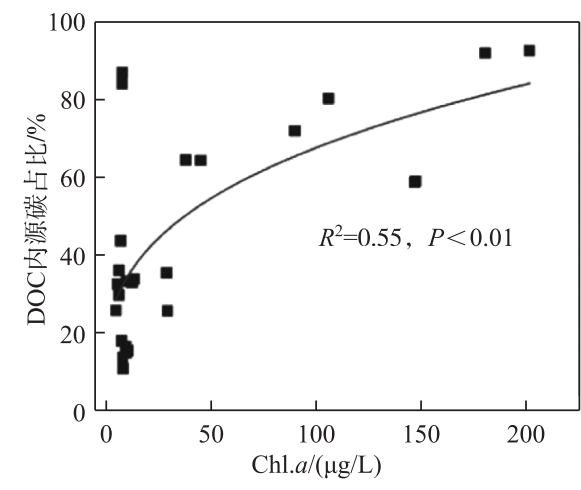

图 2 水库 DOC 内源碳占比与 Chl. $a$ 浓度的关系

Fig.2 Relationship between the ratio of endogenous carbon to DOC and Chl. $a$ in the reservoirs
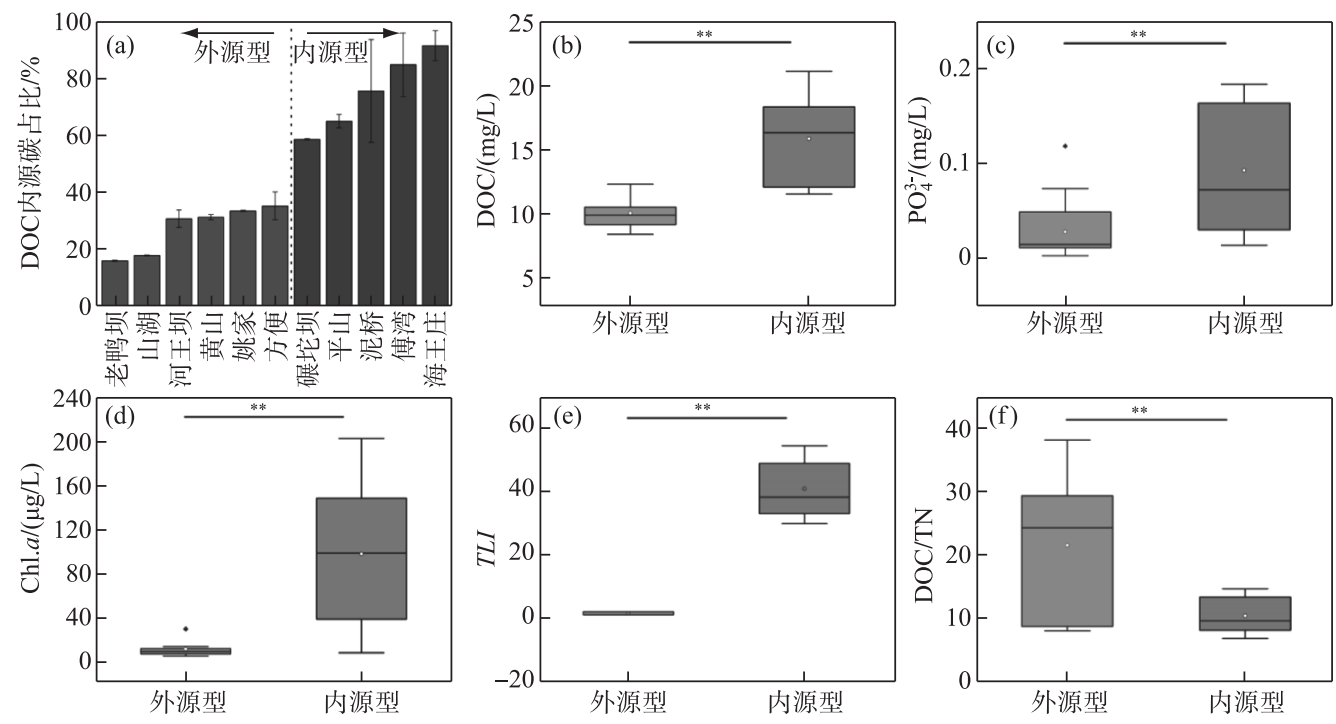

图 3 内外源水库中 $\mathrm{DOC} 、 \mathrm{PO}_{4}^{3-} 、 \mathrm{Chl} . a 、 T L I$ 以及 $\mathrm{DOC} / \mathrm{TN}$ 的差异

（ *表示显著性水平 $<0.05 ; * *$ 表示显著性水平 $<0.01)$

Fig.3 Difference of DOC, $\mathrm{PO}_{4}^{3-}$, Chl. $a$, TLI and DOC/TN between the exogenous and endogenous reservoirs

浮游细菌的呼吸代谢速率在内外源水库中也存在着较大差异 (图 5). 在外源型水库中, 黄山水库浮游 细菌的呼吸代谢碳速率最高为 $(30.46 \pm 1.82) \mu \mathrm{g} /(\mathrm{L} \cdot \mathrm{h})$, 方便水库中浮游细菌的呼吸代谢碳速率最低为 $(2.86 \pm 0.03) \mu \mathrm{g} /(\mathrm{L} \cdot \mathrm{h})$. 在内源型水库中, 浮游细菌呼吸代谢碳速率的范围为 $3.91 \sim 32.29 \mu \mathrm{g} /(\mathrm{L} \cdot \mathrm{h})($ 图 5 a). 呼吸代谢产物 $\mathrm{CO}_{2}$ 中碳稳定同位素特征值 $\left(\delta^{13} \mathrm{C}_{\text {呼吸 }}\right.$ ) 的范围为 $-31.48 \% 0 \sim-22.72 \% 0$ (表 3 ). 双元混合模型 的计算结果表示, 内外碳源对不同水库浮游细菌呼吸代谢的贡献率存在差异. 外源型水库中, 内源碳对呼吸 代谢的贡献率为 $12.72 \% \sim 83.80 \%$; 内源型水库中, 内源碳对呼吸代谢的贡献率为 $34.94 \% \sim 81.70 \%$.

在浮游细菌生产和呼吸代谢基础上, 分析了细菌转化 DOC 的总体代谢速率. 外源型水库河王坝浮游细 菌代谢 DOC 总速率最高, 为 $(49.48 \pm 1.56) \mu \mathrm{g} /(\mathrm{L} \cdot \mathrm{h})$, 代谢外源碳和内源碳速率分别为 $(27.86 \pm 2.60)$ 和 (21.61 \pm 0.52$) \mu \mathrm{g} /(\mathrm{L} \cdot \mathrm{h})$, 其次为海王庄、黄山和泥桥水库 (图 6a). 山湖水库中浮游细菌代谢外源碳速率最 
低, 为 $(0.78 \pm 0.26) \mu \mathrm{g} /(\mathrm{L} \cdot \mathrm{h})$; 在傅湾水库中细菌代谢内源碳速率最低, 为 $(3.13 \pm 0.26) \mu \mathrm{g} /(\mathrm{L} \cdot \mathrm{h})$.

表 3 浮游细菌代谢产物中碳稳定同位素的特征值以及内外源贡献分析“

Tab.3 The characteristic values of stable carbon isotope of bacterial metabolite and contribution rates of endogenous/exogenous carbon to bacterial metabolite

\begin{tabular}{cccccccc}
\hline 水库 & 水库类型 & $\delta^{13} \mathrm{C}_{\text {生产 }} / \% 0$ & $\delta^{13} \mathrm{C}_{\text {呼吸 } / \% 0}$ & 生产内 $\%$ & 生产外 $\%$ & 呼吸内 $\%$ & 呼吸外 $\%$ \\
\hline 山湖 & 外源型 & -28.40 & -29.36 & 24.96 & 75.04 & 36.16 & 63.84 \\
老鸭坝 & 外源型 & -29.82 & -31.48 & 48.64 & 51.36 & 83.80 & 16.20 \\
河王坝 & 外源型 & -24.68 & -25.93 & 65.86 & 34.14 & 27.43 & 72.57 \\
黄山 & 外源型 & -27.36 & -22.72 & 78.31 & 21.69 & 12.72 & 87.28 \\
姚家 & 外源型 & -29.81 & -30.30 & 44.32 & 55.68 & 50.53 & 49.47 \\
方便 & 外源型 & -29.83 & -29.67 & 59.68 & 40.32 & 57.18 & 42.82 \\
碾坨坝 & 内源型 & -24.01 & -24.46 & 90.50 & 9.50 & 80.23 & 19.77 \\
平山 & 内源型 & -22.39 & -25.41 & 10.55 & 89.45 & 64.12 & 35.88 \\
泥桥 & 内源型 & -27.64 & -24.75 & 78.13 & 21.87 & 41.30 & 58.63 \\
傅湾 & 内源型 & -27.34 & -27.27 & 48.12 & 51.88 & 34.94 & 65.06 \\
海王庄 & 内源型 & -22.76 & -25.64 & 42.69 & 57.31 & 81.70 & 18.30 \\
\hline
\end{tabular}

*生产内 \% 表示生产代谢中内源碳的占比,生产外 \% 表示生产代谢中外源碳的占比; 呼吸内\% 表示呼吸代谢中内源碳的占 比,呼吸外\%表示呼吸代谢中內源碳的占比.

\section{3 浮游细菌碳代谢过程影响因素分析}

对浮游细菌生产和呼吸代谢过程的分析显示, 内源型水库中, 随着 Chl. $a$ 浓度的增加, 浮游细菌生产代 谢内源碳速率显著增加 $(P<0.05)$, 但总生产代谢速率及生产代谢外源碳速率与 Chl. $a$ 浓度无显著相关性 $(P>0.05)$ (图 4b) ; 而在外源型水库中, Chl. $a$ 浓度与生产代谢速率及不同来源碳的生产代谢速率的关系弱 $(P>0.05)$ (图 4c). 随着 Chl. $a$ 浓度的升高, 内源型水库浮游细菌总呼吸代谢速率及呼吸内外源碳速率无明 显变化特征 (图 5b). 而外源型水库中细菌呼吸代谢速率与呼吸内源碳速率均随 Chl. $a$ 浓度的升高而显著增 加 $(P<0.01)$ (图 5c). 上述结果显示, 不同类型的水库中, 初级生产力增加对系统中浮游细菌生产和呼吸过 程产生的影响不同. 特别是外源型水库中, 初级生产力增加显著促进了呼吸代谢过程.
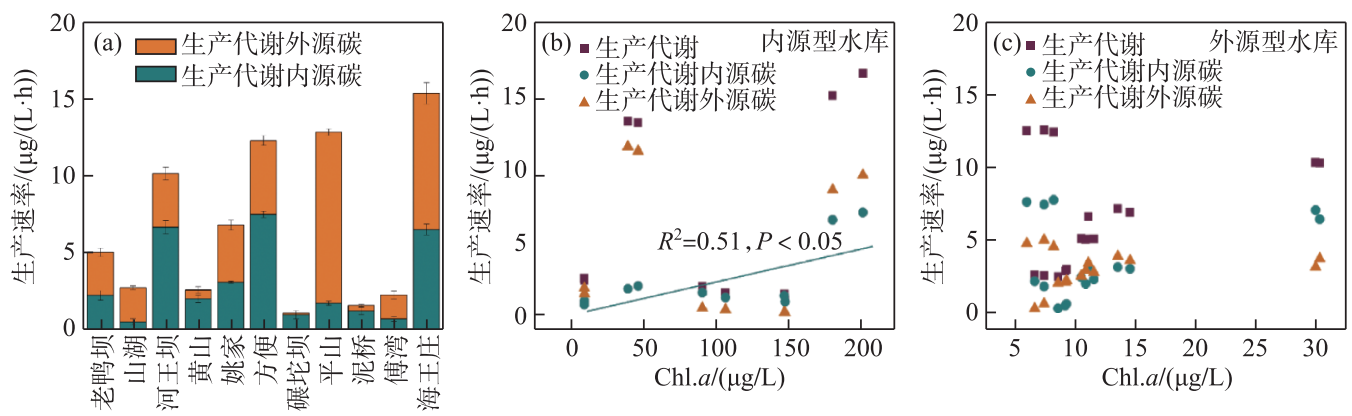

图 4 水库浮游细菌的生产代谢速率 (a)、Chl. $a$ 浓度与内源型水库 (b) 以及外源型水库 中细菌生产代谢速率 $(\mathrm{c})$ 的关系

Fig.4 Bacterial production rates in the reservoirs (a) and relationships between the Chl. $a$ concentration and bacterial production rates in the endogenous (b) and exogenous (c) reservoirs

在内源型水库中, 水体 Chl. $a$ 浓度与浮游细菌代谢内源 DOC 速率存在着显著正相关关系 $(P<0.01)$ ( 图 $6 \mathrm{~b})$, 而在外源型水库中, Chl. $a$ 浓度不仅与代谢内源碳速率而且与浮游细菌代谢 DOC 速率均存在显著的正相 关关系 $(P<0.05)$ (图 6c). 总体上, 随着水体 Chl. $a$ 浓度增加, 细菌代谢内源 DOC 的速率显著升高 (图 6).

本研究中去除温度的偏相关分析结果显示: 在内源型水库中, 随 $\mathrm{NO}_{3}^{-}$和 $\mathrm{PO}_{4}^{3-}$ 浓度的升高, 浮游细菌呼吸 

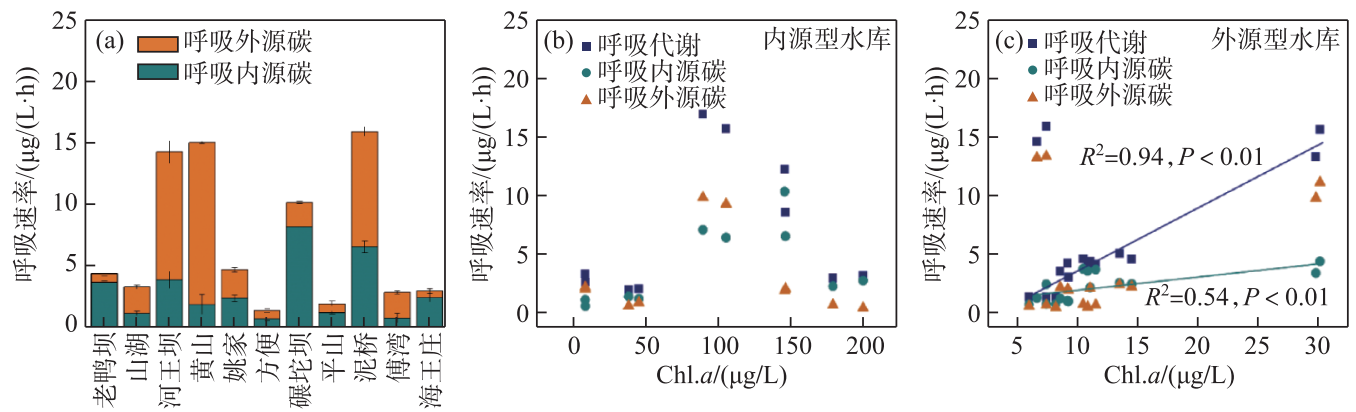

图 5 水库浮游细菌的呼吸代谢速率 (a)、Chl. $a$ 浓度与内源型水库 $(b)$ 以及 外源型水库 $(\mathrm{c})$ 中细菌呼吸代谢速率的关系

Fig.5 Bacterial respiration rates in the reservoirs (a) and relationships between the Chl.a concentration and bacterial respiration rates in the endogenous (b) and exogenous (c) reservoirs
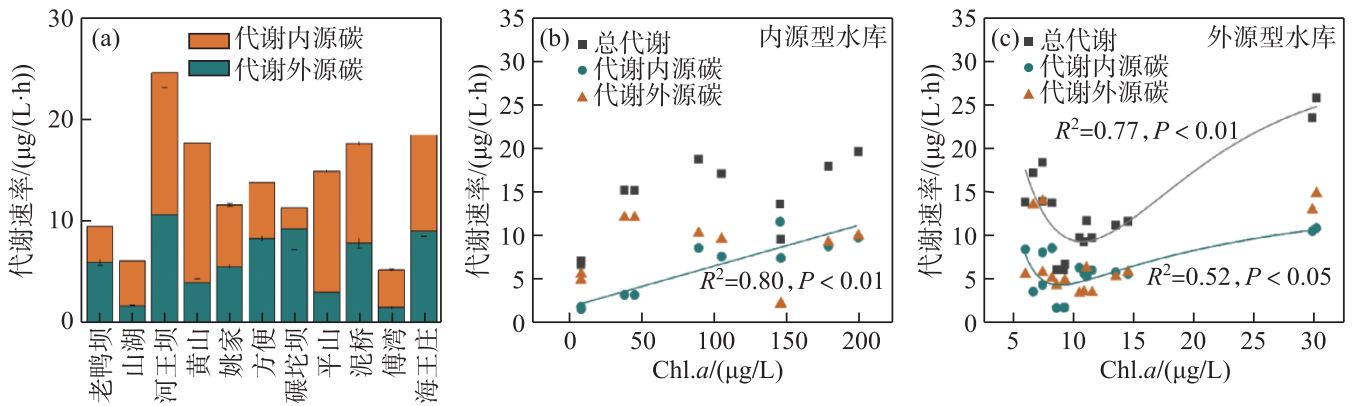

图 6 水库浮游细菌的代谢速率 (a)、Chl. $a$ 浓度与内源型水库 $(\mathrm{b})$ 以及 外源型水库 $(\mathrm{c})$ 中细菌代谢速率的关系

Fig.6 Bacterial metabolic rates in the reservoirs (a) and relationships between the Chl.a concentration and bacterial metabolic rates in the endogenous (b) and exogenous (c) reservoirs

速率显著下降 $(P<0.05)$ ( 图 7a) ; 但外源型水库浮游细菌呼吸速率随两种营养盐离子的升高而显著增加 $(P<0.05)$ ( 图 7b)

通过逐步回归方法,将不同碳源类型浮游细菌呼吸速率与环境因子建立关系 (表 4). 在内源型水库中,
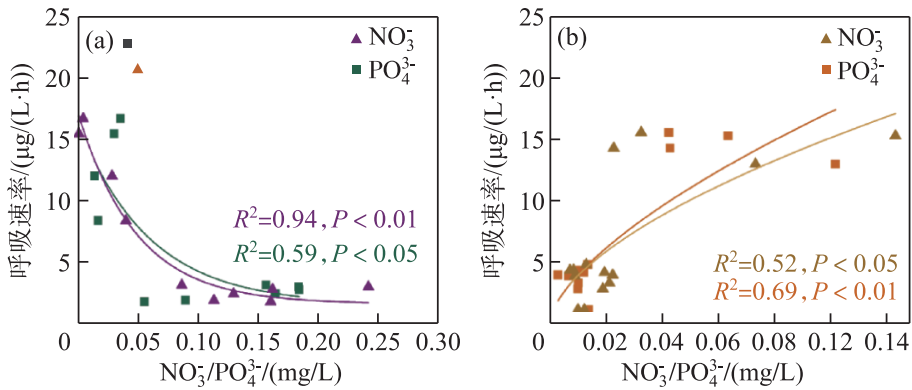

图 $7 \mathrm{NO}_{3}^{-}$和 $\mathrm{PO}_{4}^{3-}$ 与内源型水库 $(\mathrm{a})$ 和外源型水库 $(\mathrm{b})$ 中细菌呼吸代谢速率的关系

Fig.7 Relationships between the $\mathrm{NO}_{3}^{-}$and $\mathrm{PO}_{4}^{3-}$ concentrations and bacterial respiration rates in the endogenous (b) and exogenous (c) reservoirs 
浮游细菌呼吸作用主要受 $\mathrm{PO}_{4}^{3-} 、 \mathrm{NO}_{3}^{-} 、 \mathrm{pH}$ 和温度的影响. 而外源性水库浮游细菌呼吸速率可通过 $\mathrm{PO}_{4}^{3-}$ 、 $\mathrm{NO}_{3}^{-}$、Chl. $a$ 、 DOC 以及溶解氧浓度进行预测. 由此可见, 在预估水体温室气体释放通量时, 在计算浮游细菌呼 吸作用部分中,需要充分考虑水体碳源类型及营养水平,选择恰达的理化指标进行更准确的预估.

表 4 浮游细菌呼吸速率与水库理化因子的关系*

Tab.4 Relationship between the bacterial respiration rate and physicochemical factors in the reservoirs

\begin{tabular}{clrr}
\hline 水库类型 & 呼吸速率方程 & 调整后 $R^{2}$ & $P$ 值 \\
\hline 内源型 & $\mathrm{BR}_{\text {内 }}=34.01\left(\mathrm{PO}_{4}^{3-}\right)-40.55\left(\mathrm{NO}_{3}^{-}\right)+4.34(\mathrm{pH})+0.47(\mathrm{Temp})-38.09$ & 0.81 & 0.001 \\
外源型 & $\mathrm{BR}_{\text {外 }}=81.61\left(\mathrm{PO}_{4}^{3-}\right)+91.65\left(\mathrm{NO}_{3}^{-}\right)-0.52(\mathrm{Chl} . a)+1.71(\mathrm{DOC})+1.85(\mathrm{DO})-29.75$ & 0.84 & 0.001 \\
\hline
\end{tabular}

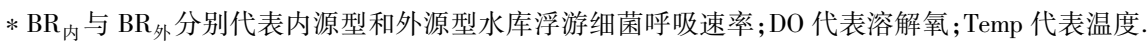

\section{3 讨论}

\section{1 水体初级生产力的提高对浮游细菌代谢过程的影响}

本研究中, 11 座水库 DOC 中的内源碳占比从 $16.17 \%$ 到 $91.67 \%$ 不等, 碳的来源呈现出明显的异质性与 复杂性, 对探究水库浮游细菌两种代谢过程中对内外源碳的利用规律无疑是个挑战 ${ }^{[22]}$. 在 11 座水库中, 随 着水库初级生产力 (Chl. $a$ 浓度) 升高, 内源碳的占比显著升高, 表明藻类是水库生态系统中内源型 DOC 的 重要补给 (图 2). 这与曾庆飞等 ${ }^{[23]}$ 在太湖的研究结果类似, 以浮游藻类为代表的内源碳对太湖湖心区域 DOC 的贡献率高达 $58.80 \% \sim 92.90 \%$. 自然水体中 DOC 浓度的升高往往伴随着氮、磷等营养物质的增多, 有 助于提高浮游细菌的碳代谢过程 ${ }^{[24]}$. Karlsson 等 $^{[25]}$ 发现在瑞典北部的 9 座贫营养型湖泊中 ( DOC 浓度小于 $4 \mathrm{mg} / \mathrm{L})$, 浮游细菌的呼吸代谢碳速率为 $3.1 \sim 9.8 \mu \mathrm{g} /(\mathrm{L} \cdot \mathrm{h})$, 生产代谢碳速率为 $0.7 \sim 6.7 \mu \mathrm{g} /(\mathrm{L} \cdot \mathrm{h})$. 本研究 中水库营养类型为中营养型和富营养型 (碾坨坝和海王庄水库为富营养), DOC 平均浓度超过 $10 \mathrm{mg} / \mathrm{L}$, 而 本研究中浮游细菌呼吸代谢碳速率为 $2.86 \sim 30.46 \mu \mathrm{g} /(\mathrm{L} \cdot \mathrm{h})$, 生产代谢碳速率为 $5.72 \sim 25 \mu \mathrm{g} /(\mathrm{L} \cdot \mathrm{h})$. 与这 些北半球高纬度地区的贫营养湖泊相比, 本研究水库中浮游细菌生产及呼吸代谢速率更高.

无论是在内源碳主导类型 (内源型) 还是外源碳主导类型 (外源型) 水库中, 随着水体初级生产力的增 加, 浮游细菌总代谢过程中对内源碳的利用速率均显著上升 (图 4b,c), 说明水体初级生产力增加对浮游细 菌代谢内源 DOC 具有一定程度的促进作用. 研究者普遍认为, 水体初级生产者释放的藻源性碳 (内源 DOC) 的生物可利用性更高 ${ }^{[26]}$, 比起芳香化程度较高的外源 DOC, 内源 DOC 存在更多的氨基酸和碳水化合物. Amon 等 ${ }^{[27]}$ 利用北极水体中的藻类 DOC ( 内源 DOC) 进行了 10 天的浮游细菌降解实验, 发现浮游细菌选择 性地利用 DOC 中容易被其降解的中性糖和氨基酸组分, 留下难降解组分. Brett 等 ${ }^{[28]}$ 学者通过大量文献调 查, 发现流人淡水生态系统中的外源性有机碳由 $80 \%$ 90\%的难以生物化学降解的木质纤维素组成, 这无疑 增加了细菌代谢陆源碳的难度. 在本研究选取的 11 座水库中, 外源型有机碳的来源主要为树叶和土壤 (表 2 ), 在水体中不易分解 ${ }^{[29]}$. 不过 Logue 等通过对加拿大数百个湖泊、河流和湿地的分析表明, 外源 DOC 中可 生物降解的 DOC 的比例仍然存在 ${ }^{[30]}$. 这也在一定程度上解释了本实验中所观察到的外源碳在两种水库细 菌代谢过程中保持一定当量的现象.

在本研究中的外源型水库中随 Chl. $a$ 浓度的增加, 呼吸速率及呼吸内源碳速率均显著增加, 这与 Guillemette 等 ${ }^{[5]}$ 对加拿大魁北克省 12 座塞营养型湖泊的研究结果一致, 外源碳主导的水体浮游细菌优先利用 内源 DOC 完成呼吸作用. 而本研究中的内源型水库中, 未发现细菌呼吸代谢与初级生产存在显著的相关关 系, 我们推测内源 DOC 不是浮游细菌呼吸作用的限制因子. 两种类型水库浮游细菌呼吸速率对水体初级生 产力升高的响应不同, 反映了不同水体细菌碳代谢特征的差异. 而浮游细菌呼吸作用是整个水域生态系统 异养呼吸作用的主体 ${ }^{[31]}$, 特别是一些初级生产力水平较低的寡营养水体, 浮游细菌呼吸强度远远超过水体 初级生产力, 使得湖库水体成为大气 $\mathrm{CO}_{2}$ 的重要释放源 ${ }^{[32]}$, 因此, 关注不同营养水平和不同碳源环境下浮游 细菌呼吸速率对了解区域 $\mathrm{CO}_{2}$ 释放具有重要意义.

\section{2 水体营养水平与浮游细菌呼吸作用的联系}

氮、磷一直被认为是淡水生态系统中限制细菌生长的主要营养成分, 其生物可利用性在很大程度上影 
响着 DOC 的累积和细菌的代谢 ${ }^{[33]}$. 呼吸作用强弱是评价浮游细菌分解代谢活性的重要指标, 更是水体 DOC 分解促使 $\mathrm{CO}_{2}$ 排放的重要环节. 异养浮游细菌的呼吸作用与有机底物浓度、碳源类型、温度、营养条件等因 素有着密切的联系 ${ }^{[31,34]}$. Sánchez 等 $^{[35]}$ 利用废水处理的光呼吸反应器进行了浮游细菌的光呼吸实验, 发现 细菌的呼吸代谢速率与水体藻源性有机碳的浓度存在着显著相关性, 并且受光强、温度、 $\mathrm{pH}$ 、营养盐离子以 及溶解氧等环境条件的共同影响.

外源型水库中 $\mathrm{NO}_{3}^{-}$和 $\mathrm{PO}_{4}^{3-}$ 浓度的升高促进了浮游细菌呼吸作用的现象, 在寡营养水体中具有一定的普 遍性 ${ }^{[36-37]}$. 可能的原因为:一方面, $\mathrm{NO}_{3}^{-}$和 $\mathrm{PO}_{4}^{3-}$ 浓度的升高使水体 $\mathrm{C}: \mathrm{N}$ 和 $\mathrm{C}: \mathrm{P}$ 的比例降低, 更有利于呼吸作 用对有机底物的分解 ${ }^{[38]}$; 另一方面, 营养盐的增加不仅为浮游细菌提供更为优良的代谢条件, 同时也为水体 初级生产者给予更充分的营养来源. 一项在河口地区的研究表明 ${ }^{[39]}$, 外源性有机物质的输人通过所携带营 养物质的增多, 刺激了内源性有机质的产生, 进而间接促进异养浮游细菌的呼吸速率. 而在本研究中, 外源 型水库中 Chl. $a$ 浓度与 DOC、 $\mathrm{TN} 、 \mathrm{NO}_{3}^{-} 、 \mathrm{PO}_{4}^{3-}$ 具有显著的正相关关系 $(r>0.7 ; P<0.01)$, 而且外源 $\mathrm{DOC}$ 主导 的水体中, $\mathrm{NO}_{3}^{-} 、 \mathrm{PO}_{4}^{3-}$ 增加导致浮游细菌呼吸速率上升. 与外源型水库相比, 内源型水库不仅优势碳源类型不 同, 其 DOC、Chl. $a$ 、及各形态氮磷浓度也更高 (图 3). Stelzer 等 ${ }^{[40]}$ 在葟营养溪流水体中构建了不同碳源类 型、不同营养梯度的实验, 发现不同类型的有机底物下浮游细菌对营养盐的响应不同. Allesson 等 ${ }^{[41]}$ 研究了 不同 DOC 和磷浓度下浮游细菌代谢特征, 发现当 DOC 浓度小于 $10 \mathrm{mg} / \mathrm{L}$ 时, 磷添加会促进浮游细菌的呼吸 作用. 而当 DOC 浓度大于 $15 \mathrm{mg} / \mathrm{L}$ 时, 有机底物对细菌代谢过程不构成限制作用, 添加了磷的处理组中浮游 细菌特异性呼吸 rRNA 基因拷贝数反而低于不添加磷的对照组. 这些发现与本研究对外源型与内源型水库 调查获得的结果相吻合. 在 Allesson 等 ${ }^{[41]}$ 的实验中, 随着水体磷元素浓度增加, 尽管细胞水平上呼吸作用降 低,但细菌生产过程反而增强,也可以表现出更高的代谢活性.

\section{4 结论}

本研究选取了南京市 11 座中小型水库, 利用碳稳定同位素技术和双端元混合模型定量分析浮游细菌 在生产和呼吸代谢过程中对内外碳源的利用. 通过对比内源型和外源型水库, 获得的主要结论:

1) 不同类型的水库随初级生产力提高, 浮游细菌生产和呼吸过程的响应不同. 对于内源型水库, Chl. $a$ 浓度升高促进了浮游细菌生产过程对内源碳的利用, 而对外源型水库, Chl. $a$ 浓度升高显著促进了浮游细菌 呼吸作用对内源碳的利用.

2) 不同类型的水库水体营养盐浓度对呼吸作用的影响不同. 内源型水库随着氮、磷营养盐浓度升高, 呼 吸作用显著减弱,而外源型水库的规律完全相反.

\section{5 参考文献}

[ 1 ] Sun H, Zhang YD, Yu JL et al. Contribution of allochthonous dissolved organic carbon to the carbon source of planktonic crustaceans in Lake Fuxian. J Lake Sci, 2017, 29(4) : 887-895. DOI: 10.18307/2017.0412. [孙欢, 张永东, 于谨磊 等. 外源溶解性有机碳对抚仙湖甲壳类浮游动物碳源的贡献. 湖泊科学, 2017, 29(4) : 887-895.]

[ 2 ] Peterson JA, McDowell WH, Neff JC. Sources, production, and regulation of allochthonous dissolved organic matter inputs to surface waters. In: Findlay S, Sinsabaugh R eds. Aquatic ecosystems: interactivity of dissolved organic matter. New York: Academic Press, 2003: 26-70.

[ 3 ] Bertilsson S, Jones JB Jr. Supply of dissolved organic matter to aquatic ecosystems: autochthonous sources. In: Findlay S, Sinsabaugh R eds. Aquatic ecosystems: interactivity of dissolved organic matter. New York: Academic Press, 2003: 3-25.

[ 4 ] Falkowski PG, Fenchel T, Delong EF. The microbial engines that drive Earth's biogeochemical cycles. Science, 2008,320 (5879) : 1034-1039. DOI: 10.1126/science.1153213.

[ 5 ] Guillemette F, Leigh McCallister S, del Giorgio PA. Selective consumption and metabolic allocation of terrestrial and algal carbon determine allochthony in lake bacteria. The ISME Journal, 2016, 10 (6) : 1373-1382. DOI: 10. 1038/ismej. 2015.215 .

[ 6 ] de Kluijver A, Yu JL, Houtekamer M et al. Cyanobacteria as a carbon source for zooplankton in eutrophic Lake Taihu, China, measured by ${ }^{13} \mathrm{C}$ labeling and fatty acid biomarkers. Limnology and Oceanography, 2012, 57 ( 4 ) : 1245-1254. 
DOI: $10.4319 /$ lo.2012.57.4.1245.

[ 7 ] Banerjee S, Schlaeppi K, van der Heijden MGA. Keystone taxa as drivers of microbiome structure and functioning. Nature Reviews Microbiology, 2018, 16(9) : 567-576. DOI: 10.1038/s41579-018-0024-1.

[ 8 ] Sundh I. Biochemical composition of dissolved organic carbon derived from phytoplankton and used by heterotrophic bacteria. Applied and Environmental Microbiology, 1992, 58(9) : 2938-2947. DOI: 10.1128/aem.58.9.2938-2947.1992.

[ 9 ] Russell JB. The energy spilling reactions of bacteria and other organisms. Journal of Molecular Microbiology and Biotechnology, 2007, 13(1/2/3) : 1-11. DOI: 10.1159/000103591.

[10] Guillemette F, McCallister SL, del Giorgio PA. Differentiating the degradation dynamics of algal and terrestrial carbon within complex natural dissolved organic carbon in temperate lakes. Journal of Geophysical Research: Biogeosciences, 2013, 118(3) : 963-973. DOI: 10.1002/jgrg.20077.

[11] Tang XQ, Guo WJ, Wu M et al. Functional deterioration and restoration measures for rural small reservoirs. J Yangtze River Scientific Research Institute, 2018, 35(2) : 17-21. DOI: 10.11988/ckyyb.20160993. [汤显强, 郭伟杰, 吴敏等. 农村 小型水库功能退化分析及恢复对策. 长江科学院院报, 2018, 35(2): 17-21.]

[12] Chen MJ, Chen FZ. Water quality evaluation and eutrophication analysis of small reservoirs in Nanjing. Environmental Protection Science, 2020, 46(4) : 87-91. [ 陈美军, 陈非洲. 南京市小型水库水质评价和富营养化分析. 环境保护科学, $2020, \mathbf{4 6}(4)$ : 87-91.]

[13] Acuña-Alonso C, Álvarez X, Lorenzo O et al. Water toxicity in reservoirs after freshwater algae harvest. Journal of Cleaner Production, 2021, 283: 124560. DOI: 10.1016/j.jclepro.2020.124560.

[14] Karlsson J, Berggren M, Ask J et al. Terrestrial organic matter support of lake food webs: Evidence from lake metabolism and stable hydrogen isotopes of consumers. Limnology and Oceanography, 2012, 57(4) : 1042-1048. DOI: 10.4319/lo. 2012.57.4.1042.

[15] Li B, Gu QJ, Miao YQ et al. Methane distribution patterns along a transect of Lake Fuxian, a deep oligotrophic lake in China. Environmental Science and Pollution Research, 2020, 27 (21) : 25848-25860. DOI: 10. 1007/s11356-01906098-7.

[16] Zhou YW, Song K, Han RM et al. Nonlinear response of methane release to increased trophic state levels coupled with microbial processes in shallow lakes. Environmental Pollution, 2020, 265: 114919. DOI: 10.1016/j.envpol.2020.114919.

[17] Zhang JY, Ni WM, Luo Y et al. Response of freshwater algae to water quality in Qinshan Lake within Taihu Watershed, China. Physics and Chemistry of the Earth, Parts A/B/C, 2011, 36(9/10/11): 360-365. DOI: 10.1016/j.pce.2010. 04.018 .

[18] Pierson-Wickmann AC, Gruau G, Jardé E et al. Development of a combined isotopic and mass-balance approach to determine dissolved organic carbon sources in eutrophic reservoirs. Chemosphere, 2011, 83 (3) : 356-366. DOI: 10.1016/j. chemosphere.2010.12.014.

[19] Li ZP, Zhang TL, Chen BY. Dynamics of soluble organic carbon and its relation to mineralization of soil organic carbon. Acta Pedologica Sinica, 2004, 41(4) : 544-552. [李忠佩, 张桃林, 陈碧云. 可溶性有机碳的含量动态及其与土壤有 机碳矿化的关系. 土壤学报, 2004, 41(4) : 544-552.]

[20] Goldenfum JA ed. GHG measurement guidelines for freshwater reservoirs. London: The International Hydropower Association, 2010: 76.

[21] Phillips DL, Gregg JW. Uncertainty in source partitioning using stable isotopes. Oecologia, 2001, 127(2): 171-179. DOI: $10.1007 / \mathrm{s} 004420000578$.

[22] Liew JH, Chua KWJ, Arsenault ER et al. Quantifying terrestrial carbon in freshwater food webs using amino acid isotope analysis: Case study with an endemic cavefish. Methods in Ecology and Evolution, 2019, 10(9) : 1594-1605. DOI: 10. 1111/2041-210x.13230.

[23] Zeng QF, Kong FX, Zhang EL et al. Effects of anthropogenic organic matter inputs on stable carbon and nitrogen isotopes in organisms from microbial food chain in Taihu Lake. Environ Sci, 2007, 28(8): 1670-1674. DOI: 10.13227/j.hjkx. 2007.08.036. [曾庆飞, 孔繁翔, 张恩楼等. 利用稳定同位素技术研究外源物质输人对太湖微食物链的贡献. 环境 科学, 2007, 28(8): 1670-1674.]

[24] Figueroa D, Rowe OF, Paczkowska J et al. Allochthonous carbon-a major driver of bacterioplankton production in the subarctic northern Baltic sea. Microbial Ecology, 2016, 71(4) : 789-801. DOI: 10.1007/s00248-015-0714-4. 
[25] Karlsson J, Jansson M, Jonsson A. Respiration of allochthonous organic carbon in unproductive forest lakes determined by the Keeling plot method. Limnology and Oceanography, 2007, 52(2) : 603-608. DOI: 10.4319/lo.2007.52.2.0603.

[26] Shen Y, Fichot CG, Liang SK et al. Biological hot spots and the accumulation of marine dissolved organic matter in a highly productive ocean margin. Limnology and Oceanography, 2016, 61(4) : 1287-1300. DOI: 10.1002/lno.10290.

[27] Amon RMW, Fitznar HP, Benner R. Linkages among the bioreactivity, chemical composition, and diagenetic state of marine dissolved organic matter. Limnology and Oceanography, 2001, 46(2) : 287-297. DOI: 10.4319/lo.2001.46.2.0287.

[28] Brett MT, Bunn SE, Chandra S et al. How important are terrestrial organic carbon inputs for secondary production in freshwater ecosystems?. Freshwater Biology, 2017, 62 (5) : 833-853. DOI: 10.1111/fwb.12909.

[29] France R, Culbert H, Peters R. Decreased carbon and nutrient input to boreal lakes from particulate organic matter following riparian clear-cutting. Environmental Management, 1996, 20(4) : 579-583. DOI: 10.1007/BF01474657.

[30] Logue JB, Stedmon CA, Kellerman AM et al. Experimental insights into the importance of aquatic bacterial community composition to the degradation of dissolved organic matter. The ISME Journal, 2016, 10(3) : 533-545. DOI: 10.1038/ismej.2015.131.

[31] Pace ML, Prairie YT eds. Respiration in lakes. Oxford: Oxford University Press, 2005.

[32] Grasset $\mathrm{C}$, Sobek $\mathrm{S}$, Scharnweber $\mathrm{K}$ et al. The $\mathrm{CO}_{2}$-equivalent balance of freshwater ecosystems is non-linearly related to productivity. Global Change Biology, 2020, 26(10) : 5705-5715. DOI: 10.1111/gcb.15284.

[33] Farjalla VF, Faria BM, Esteves FA. The relationship between DOC and planktonic bacteria in tropical coastal lagoons. Archiv Für Hydrobiologie, 2002, 156( 1) : 97-119. DOI: 10.1127/0003-9136/2002/0156-0097.

[34] Rodibaugh KJ, Becker JC, Timmins G et al. Physicochemical and carbon quantity-quality gradients equally influence bacterial carbon metabolism across an arid riverscape. Aquatic Ecology, 2020, 54(3) : 677-696. DOI: 10.1007/s10452-02009767-9.

[35] Sánchez Zurano A, Gómez Serrano C, Acién-Fernández FG et al. Modeling of photosynthesis and respiration rate for microalgae-bacteria consortia. Biotechnology and Bioengineering, 2021, 118(2) : 952-962. DOI: 10.1002/bit.27625.

[36] Cimbleris ACP, Kalff J. Planktonic bacterial respiration as a function of C: N ratios across temperate lakes. Hydrobiologia, 1998, 384(1) : 89-100. DOI: 10.1023/a: 1003496815969.

[37] Jansson M, Bergström AK, Lymer D et al. Bacterioplankton growth and nutrient use efficiencies under variable organic carbon and inorganic phosphorus ratios. Microbial Ecology, 2006, 52(2) : 358-364. DOI: 10.1007/s00248-006-9013-4.

[38 ] Weigel BL, Pfister CA. The dynamics and stoichiometry of dissolved organic carbon release by kelp. Ecology, 2021,102 (2) : e03221. DOI: 10.1002/ecy.3221.

[39] Soares ARA, Berggren M. Indirect link between riverine dissolved organic matter and bacterioplankton respiration in a boreal estuary. Marine Environmental Research, 2019, 148: 39-45. DOI: 10.1016/j.marenvres.2019.04.009.

[40] Stelzer RS, Heffernan J, Likens GE. The influence of dissolved nutrients and particulate organic matter quality on microbial respiration and biomass in a forest stream. Freshwater Biology, 2003, 48 (11): 1925-1937. DOI: 10.1046/j. 13652427.2003.01141.x.

[41] Allesson L, Andersen T, Dörsch P et al. Corrigendum: phosphorus availability promotes bacterial DOC-mineralization, but not cumulative $\mathrm{CO}_{2}$-production. Frontiers in Microbiology, 2020, 11: 569879. DOI: 10.3389/fmicb.2020.569879. 